\title{
A Study on the Aspects of Successful Business Intelligence System Development
}

\author{
Il Seok Ko and Sarvar R. Abdullaev \\ Division of Computer and Multimedia, Dongguk University, 707 Seokjang-dong, \\ Gyeongju-si, Gyeongsangbuk-do, 780-714 Korea \\ isko@dongguk. edu
}

\begin{abstract}
Business Intelligence (BI) Systems are today considered as a major strategic tool of many well-established companies like Lufthansa, TDC Telecom and AT\&T. Of course, the knowledge derived from the experience of those companies could be helpful guide in building efficient BI Systems. Thus, this study highlights the main points arisen from the worldwide practice of building successful BI Systems. The managers usually expect from BI Systems the acceleration of their decision-making process while keeping the quality of each decision, the enhancement of their product development cycle, the maximization of the profit from existing product lines and the discovery of new opportunities, the establishment of better marketing with robust CRM. However, more than $50 \%$ of BI projects fail to meet these requirements. So this study investigates the critical mistakes commonly made by BI System developers and suggests profound solutions from the best BI practices.
\end{abstract}

Keywords: business intelligence, failure of BI, successful BI cases.

\section{Introduction}

What made people build BI Systems? IBM gives the clear definition of BI: "Business intelligence means using your data assets to make better business decisions. It is about access, analysis, and uncovering new opportunities." By the end of 90s, big corporations found out that they have huge amount of unused historical data accumulated from their daily activities. So the people started to mine that useless data and consequently gained useful knowledge.

Generally speaking, we can split the BI evolution into 3 stages. Initially, there have been business information systems aimed at accomplishing limited range of operational business activities and, in the same way, storing the operational data. Almost all decisions had to be made leaning on operational data and sometimes that made a clash. At the second stage, the historical data has been separated from operational data into data warehouses which are specially tailored to store and provide quick access to such data. It also summarized the data in various cuboids and consequently eased the decision making process. Finally, today's BI systems have been discovered by involving data mining techniques and artificial intelligence in order to extract knowledge for decision making. 
In this paper we will consider both successful cases of BI system deployment and also study commonly made critical mistakes while building BI system.

\section{Why Do BI Projects Fail?}

More than half of BI projects fail to meet the requirements stated at the beginning of the project. Commonly these are the requirements aimed at facilitating the process of decision making and identifying new business opportunities by the utilization of accumulated historical data. However these goals are not always met, and there are several reasons for that.

Mostly BI projects considered to be the inner project which should meet the company's internal requirements. However it should reflect the needs of customers and deal with external issues like market situation or customer's behavior. On the other hand, there is always gap between the actual implementers and the users of the system, and sometimes it becomes technology oriented project which aimed at outrunning in technological perspective. Nonetheless, it is a false ideology. BI should be done toward business perspective of the company. As the BI project is organization-wide project, it should involve members from each department especially from Marketing and Sales departments who are appeared to be the end-users of knowledge mined out from BI system.

BI projects are organization specific project, so they have to be unique implementation methodology where the project deliverables and goals should be stated clearly. BI development is an incremental process which never stops getting improved. Unlike OLTP systems, BI system never reaches the end, as it continues evolving and acquiring new functionalities. As BI used for achieving strategic goals, there is no definite set of deliverables which constitute the completeness of BI system and they always change. On the other hand, the project should be properly planned before kicking it off. It include stages like requirements gathering, identifying the condition of available data sources, cost estimation, risk assessment, identifying the success factors, preparation of project charter and issuance of high-level project plan.

Also, the standardization of each process and data makes the things much comprehensive and kills ambiguities. Therefore there should be a thorough standard which makes the teamwork coherent. Along with unique standard, there should be data quality control. As the quality of the knowledge directly connected to the quality of inputted data, the rules on cleansing the dirty data should be accepted. Additionally, there should be metadata repository which gives the context to stored data. We can divide metadata into two types: technical and business. Technical metadata defines the algorithms and the definition of database while business metadata gives unambiguous definition of business elements like sales, products and etc.

BI developers usually strive to implement everything, but in many cases it is hardly achieved and sometimes it causes many problems associated with the continuation of the project or maintaining the bundle of tools which are not rather used. There are three major applications should be included in any BI system:

1. ETL services

2. Data warehouse and integrated OLAP

3. Front-end application 
It is worthwhile to say that if to take into account all issues that have been mentioned above, the BI project is likely to payoff and to reach its ultimate goals like increase in sales, efficient product development cycle, minimized expenses, better loyalty of customers and, of course, discovery of new business opportunities.

\section{Successful BI Cases}

In this section, we will discuss a couple of different BI cases implemented on various platforms.

\subsection{Microsoft Case Study: TDC Telecom}

TDC is the Denmark's telecommunication leader with annual revenue of $\$ 8$ billion is spread over 12 countries. Recently it implemented SQL Server 2005 to integrate 6 terabytes of data from over 60 disparate sources into one data warehouse and to harvest much knowledge from that data. The company was in need of Business Intelligence system which would integrate the data from various sources and would possess following features:

- Integrate all data into a data warehouse through ETL to provide a single "version of the truth."

- Create multidimensional cubes to support data analysis.

- Reduce the cost of analyzing disparate data.

The BI solution provided by Microsoft Corp. with the use of technologies such as Microsoft SQL Server 2005 (64-bit) Enterprise Edition, Microsoft SQL Server Analysis, OLAP and Reporting Services on the Microsoft Windows Server 2003 (64-bit) Enterprise Edition had a new name called CUBUS. Firstly, CUBUS adopted single standard for interpreting the data and met the requirement of single "version of the truth" which was stated above. It integrated the available data into one source which, in turn, maintained the consistency of data. Also even the data is stored in one source the views for that data could differ upon the analyst's preference. The single standard also included the definition of each data construct stored in separate metadata repository. That enabled business analysts to understand the context of each data and consequently make appropriate decisions. Similarly, with help of multidimensional cubes the terabytes of data has been efficiently stored and summarized which led to $80 \%$ reduction of processing time. Moreover the success of this BI project could be proven through high motivation of key business representatives in building such system.

\subsection{Oracle Case Study: Etos}

Etos is the major supermarkets chain scattered over Neitherland with its 450 outlets. Before it started to promote brands of other foreign stores, it had operated single database. But with the integration of different foreign stores, its overall IT infrastructure has become heterogeneous which consequently posed new challenges. Etos needed a centralized collection point from which to gather information on pointof-sale purchases, product range, pricing, and special offers. 
The Oracle platform appeared to be the best choice as a ground for comprehensive business intelligence environment. Setting up a data warehouse with Oracle Warehouse Builder, Oracle Database, Oracle Portal, Oracle Reports and Oracle Discoverer, made it possible to access business data in any required combination. Now it has integrated data into one point and it could be viewed by means of graphs and tables. It makes possible to store historical data and facilitates the job of analysts while examining the precise trend.

The integration of information from procurement, logistics, and sales systems made it possible to monitor the actual picture of how every part of the retail business is performing. For example, BI discovered much knowledge about how particular products are selling well in a particular region and how their shelf-position affects sales.

\section{Conclusion}

To sum up, there are several challenging points in developing BI and they are often overlooked by BI developers which, in turn, could lead to failure of BI project. We can summarize these points one more:

- Not internal requirements, but market and customer requirements.

- Dedicated business representation from each department.

- Availability of skilled team members.

- Unique BI development methodology.

- Thorough project planning.

- Data standardization.

- Date quality control.

- Existence of metadata.

- Implementation of only required tools.

On the other hand, some BI projects survive and meet their final requirements. These BI projects usually accomplished by popular software vendors like Microsoft, Oracle, SAP and etc. But on the bottom line, the success of BI project depends on how BI team members cope with those challenging points mentioned above.

\section{References}

1. Shaku Atre, "The Top Ten Critical Challenges For Business Intelligence Success", Computerworld Custom Publishing, (2003).

2. Larissa T. Moss, Shaku Atre, "Business Intelligence Roadmap - The Complete Project Lifecycle for Decision-Support Applications", Addison Wesley, (2003)

3. Roman Bukary, "Top 10 BI Traps", BI Strategic Directions, CIO, (2006)

4. Maria Sueili Almeida et al, "Getting Started with Data Warehouse and BI", IBM, (1999)

5. Nils H. Rasmussen et al, "Financial Business Intelligence: Trends, Technology, Software Selection, and Implementation", Wiley, (2002)

6. www.oracle.com, "Etos Adopts Business Intelligence Approach for Its 450 Outlets" (last accessed: 14.12.2006)

7. www.microsoft.com, "Denmark Telecom Leader Cuts with 6 Terabyte Data Warehouse on SQL Server 2005" (last accessed: 14.12.2006) 